\title{
Evaluation of A Simulation-Based Clinical Preparation Program by Final-Year Medical Students: A Qualitative Study on Emergency Patient Management
}

\section{Dilek Kitapcioglu}

Acibadem Mehmet Ali Aydinlar University

Ozlem Tanriover

Yeditepe University

Sinem Yildiz Inanici

Marmara University

Mehmet Emin Aksoy

Acibadem Mehmet Ali Aydinlar University

Mehmet Ali Gulpinar ( $\nabla$ mali.gulpinar@gmail.com )

Marmara University

\section{Research Article}

Keywords: Simulation and medical education, clinic preparation/transition programs, clinical learning environment, program evaluation

Posted Date: January 28th, 2021

DOl: https://doi.org/10.21203/rs.3.rs-152440/v1

License: (c) (i) This work is licensed under a Creative Commons Attribution 4.0 International License.

Read Full License 


\section{Abstract}

Background: The most common problem encountered by medical students is the management of unstable emergency patients. Simulation-based education (SBE) is widely used for improving the management of unstable patients. In this study, the aim is to evaluate the SBE Clinical Preparation Program and to understand whether our final-year medical students could transfer the skills acquired in the program to clinical encounters in their emergency medicine clerkship, with the aim of easing this transition.

Materials and methods: Final-year medical students at the Acıbadem Mehmet Ali Aydınlar University Faculty of Medicine and their educators were included in this qualitative study. After participating in the SBE Clinical Preparation Program for two weeks, interns completed a two-month emergency medicine clerkship. At the end of the clerkship, four focus group discussions with 5 or 7 interns $(n=24)$ and in-depth interviews with two educators were held. The digital audio recordings were transcribed verbatim within 48 hours of the interviews. The texts were reviewed by two different researchers, and thematic codes were identified.

Results: In this study, the effectiveness of the SBE Clinical Preparation Program was evaluated. The participants stated that the program prepared them very well for critical patient management and that the content of the program was sufficient and comprehensive. The trainers stated that the simulation program prepared the students well for the clinic and provided a strong foundation, which was very important, but the students had to overcome an emotional barrier when approaching real patients, a process that took one or two weeks. The characteristics of the students (motivation, anxiety levels), the quality of the processes experienced during the program (seeing a sufficient number of patients, communication and interaction with other healthcare professionals and patients) and the environment/context in which these practices took place (learning climate) were the important factors influencing the transfer of the learning outcomes to the clinical environment.

Conclusion SBE transition programs are effective in preparing students for the management of critical patients and facilitate the transition to the clerkship. SBE programs are not sufficient by themselves and should be developed in a continuous and integrated manner with training programs in actual clinical settings.

\section{Introduction}

Medical training involves stressful and uncertain transition periods, such as the beginning of medical education, the transition from the preclinical education period to the clinic and the transition from the clinical education period to professional life after graduation $(1,2,3,4,5)$. The most difficult among these periods is the start of one's professional career after graduation. The beginning of the internship training period, in which students take responsibility for patients with a supervisor and become active members of healthcare teams, is also a stressful transition period. In this context, it is important to increase 
experiential learning opportunities (in simulated environments and through work-based learning) with new learning methods and models starting from the pre-graduation period to facilitate the transition of learners $(6,7,8,9,10,11)$.

Timely, accurate and appropriate intervention is critical in emergency patient management. Previous studies have shown that the area where students feel most unprepared is emergency patient management; courses and training modules have been implemented to strengthen this competence, and the outcomes of these learning activities have been evaluated $(8,12)$. Simulation-based education (SBE) is a significant component of emergency medicine (EM) training programs, as it allows learners to develop necessary core knowledge, skills, and attitudes without exposing patients to unnecessary risk $(13,14,15,16,17,18,19)$.

Program evaluation studies provide evidence of the effectiveness of SBE applications for the acquisition of both technical and nontechnical competencies in critical/emergency patient management. Evaluations have shown that such courses and programs are beneficial in preparing doctors for emergency situations $(3,5,8)$. In line with the results obtained from these studies, students encounter difficulty with the following in clinical education: prescribing, the management of complex patients, time management and prioritization of tasks, anxiety caused by increasing duties and responsibilities, problems with peers, and ethical problems experienced in the process of consent and resuscitation $(1,10,14)$.

In Turkey, there are similar problems among new graduates with regard to critical patient management. At our university, it was determined that the curriculum in the pre-graduation training program did not provide enough opportunities, especially regarding critical patient management. As a result of this needs analysis, a two-week SBE preparation program (the SBE Clinical Preparation Program) with a focus on critical patient management was designed and integrated into the curriculum.

Experiential learning that is carried out with real cases or scenarios in both real and simulated environments generally follows the four-stage cyclic learning process described by David A. Kolb. Recently, there has been a shift from a more individual perspective to a more sociocultural perspective following the constructivist approach, and theories such as social learning and situational/contextual learning have started to dominate. Criticisms began to emerge that, as outlined in Kolb's theory, learning is too complex to take place in four consecutive stages and that social interaction has been ignored in the understanding of learning as internal interpretation and interpretation based on experience $(20,21,22,23,24)$. In this context, in evaluating the effectiveness of a training program, it must be acknowledged that the clinical learning environment of learners, such as the educator support they receive and their interactions with patients and other healthcare professionals, is an important factor influencing the transfer learning outcomes $(25,26,27,28,29)$. Program evaluation studies must be multidimensional.

In this study, the aim is to evaluate, in terms of process, output and context, the effectiveness of the SBE Clinical Preparation Program, which was prepared with a focus on emergency patient management, as a transition program into the clerkship at the Acıbadem University Faculty of Medicine. 


\section{Materials And Method}

\section{Research Type and Research Design}

In this study, the effectiveness of the SBE Clinical Preparation Program, which was integrated into the curriculum for the preparation of intern students for unstable patient management, was evaluated in the context of both the preparation program and the emergency internship. By using a qualitative method, the program was evaluated multidimensionally in terms of process, output and context (learning context and clinical context). To evaluate the process and output of the preparation program and the emergency internship program, interviews were held with students and trainers. To assess the context, in the interviews with the students and educators, participants were asked questions about the learning context and the clinical and institutional context.

In this qualitative study, the participants consisted of interns studying at Acibadem Mehmet Ali Aydinlar University Faculty of Medicine during the 2019-2020 academic year. After approval was obtained from the Institutional Ethical Committee and written consent was obtained from all of the participants, the interns were included without any exclusion criteria.All methods were performed in accordance with the relevant guidelines and regulations. Intern doctors attended the SBE Clinical Preparation Training Program, which lasted a total of 10 days, before starting the emergency medicine internship. While developing this program, first, a needs assessment was carried out, and the competencies of the program were then defined. In this process, emergency medicine specialists, anesthesiologists, family physicians and pediatricians worked together, and all the educators participated in a faculty development program for SBE. The aim of this training program was to prepare interns for emergency patient management (management of altered mental status, shortness of breath, and chest pain; multi-trauma management; and cardiopulmonary resuscitation) in the clinic as well as to help them develop teamwork, communication, leadership and decision-making skills. The program was carried out at the Acibadem Mehmet Ali Aydinlar University CASE (Center for Advanced Simulation and Education) Simulation Center, which has actual medical equipment and advanced patient simulators.

\section{Clinical Preparation Training Program and Emergency Medicine Internship Program}

The main tasks and competencies (program outcomes) that were expected to be acquired at the end of the SBE Clinical Preparation Training Program were emergency patient management and related competencies. The program aims to train learners to evaluate a patient in accordance with the algorithms for unstable emergency patient management and make the necessary first intervention. The competencies of this main task and thus the outcomes of the program are defined as follows: diagnosis of unstable patients, management of unstable patients according to the ABCDE (airway, breathing, circulation, disability, exposure) algorithm, teamwork in emergencies, effective communication, situational awareness, correct definition of the problem and decision-making. In accordance with the schedule for each day and in line with the session outcomes, after 40 minutes of theoretical training, a two-hour interventional skills session followed by 4-hour simulation scenarios and reflection sessions 
were held. Each scenario lasted 15-20 minutes, followed by the reflection/debriefing session, which lasted 35-40 minutes.

\section{Data Processing and Analysis}

\section{Focus Group Discussions}

Focus group discussions were held with students selected on a voluntary basis from among the interns who attended the training. An information meeting was held for the students on the subject, and willing students were included in the study. Students who agreed to participate in the study were invited to the meeting room where the interview would take place. There were 20-24 students in each of the four internship groups. Groups comprising 5-7 of these students were formed for the focus group interviews, and a total of 24 people were interviewed. The academic achievement levels of the students who participated in the interviews were moderate; $58 \%$ were female, $42 \%$ were male, and the average age was 24.2. The interviews with the student groups were held at different times during the last week of the emergency internship. The interviews were held in a meeting room at Atakent Acıbadem Hospital, and each focus group meeting lasted between 60 and 90 minutes. The initial plan was to interview eight groups. However, during the focus group interviews, saturation was reached after the fourth group, and further interviews were not conducted because no new data emerged.

The interviews with the focus groups were carried out with a facilitator and an observer around a table in the meeting room reserved for this task. At the beginning of the interview, the participants were informed about its subject and purpose, and their consent for the enrollment and verbal consent for the study were obtained. The interviews were recorded both by an audio recording device and by the observer. The interviewers were trainers who were not actively involved in the learning process of the students. One of the interviewees was a faculty member in the medical education department, and the other was a family medicine faculty member.

In the interviews, the experiences of the students during both the SBE Clinical Preparation Program and the emergency medicine internship were discussed. The programs were evaluated in terms of the learning process, outcomes and context (i.e., the learning, clinical and institutional contexts). Interns complete their emergency medicine internship in two hospitals, both of which are affiliated with the university. Interns spend two weeks in the advanced simulation center at the university campus prior to a two-month emergency medicine clerkship at the hospital. In this process, there are a sufficient number of trainers in all training/clinical settings, interns can be trained in small groups, and their development can be followed individually. Both hospital settings provide tertiary patient care and have a sufficient number of nurses and medical staff.

In the focus interview, qualitative data were obtained using a semistructured interview form that contained the following questions: 
1-What would you like to say about the effectiveness of the SBE Clinical Preparation Program you completed in the simulated environment?

2-How would you evaluate your bedside experiences in the real clinical environment during the emergency medicine internship?

3-How would you evaluate the learning climate and clinical climate in which your trainings took place? Describe the clinical learning context and institutional context and the effects of these contexts on learning processes and outcomes.

4- How and in what way did the emergency medicine internship affect your development in terms of managing critical patients?

\section{In-depth interviews}

In addition to focus group interviews with students to determine the emergency medicine internship learning process and the factors affecting this process, in-depth interviews were also held with faculty members in the emergency medicine department. In-depth interviews were carried out with two faculty members responsible for the emergency medicine internship, and they were also emergency department physicians in the hospital where the students studied. The two trainers were interviewed separately. The trainers were similar in terms of gender, period of specialization and age. Qualitative data were obtained through a semistructured interview form, which contained the following questions:

- What do you think about the students who completed the SBE Clinical Preparation Program prior to coming to the emergency department?

- To what extent could they transform the competencies gained in the preparation program to the clinic?

- How was their development during the emergency medicine internship in the clinical setting?

At the end of the emergency internship at Atakent Hospital, an informative meeting was held for the trainers, and they were included in the study on a voluntary basis. Two trainers who agreed to participate in the study were invited to the meeting room where the interview would take place. An in-depth interview was held with a facilitator and an observer around a table in the meeting room reserved for the meeting. At the beginning of the interview, the participants were informed about its subject and purpose, and their consent for the registration and verbal consent for the study were obtained. The interviews were recorded both by a voice recording device and by the observer. Each meeting lasted approximately one hour. First, the focus group interviews with the students and the digital audio recordings of the in-depth interviews with the educators were turned into written texts. These texts were sent to the students who were interviewed, and the feedback of the participants was reviewed. Later, the texts were reviewed independently by two different researchers (the trainers who conducted the interviews), thematic codes were extracted, and themes were extracted by grouping. The emerging themes were reviewed by the third 
and fourth researchers (a medical educator and a psychologist who did not participate in the interviews), and the themes were finalized.

\section{Results}

As a result of the analysis of the focus group interviews with the students and in-depth interviews with the two trainers, four main themes and subthemes related to these themes, which are presented in detail in the findings section, emerged (Table 1).

Table 1: List of the themes and subthemes that emerged as a result of content and thematic analysis 


\section{Main themes}

1. Thoughts on the simulation-based preparation program
Subthemes

Adequacy of the training content and implementation process
Items related to the subthemes

Comprehensive and well-structured program

Competency in unstable patient management

The need to practice stable patient management as well

Preparation for the clinical setting Safe patient intake

Decreased anxiety level

Efficient use of algorithms

Ability to manage an unstable patient

Benefits and differences from the real clinical environment

2. Experiences in the clinical setting
Emotions during real patient encounters
Emotions, emotional load and the process of getting used to the clinical environment

Relationships with and emotion management for patients and their relatives

Definition of roles and responsibilities

Relationships with other healthcare professionals and conflict management

Needing more autonomy
The number of unstable patient encounters and diversity of patients

Low number and variety of unstable patients

Differences between clinical settings

Differences between groups and learners

The most difficult situations encountered in the real clinical environment
Uncertainty in roles and responsibilities

Communication and social/interactional problems with other healthcare professionals

Intensity of working hours

Immediate involvement by 
supervisors in case of failure

3. Perceptions of the learning climate
Communication and collaboration with the educators
Supportive, safe and positive learning environment

The need to have more autonomy

Communication and collaboration Not being accepted as a doctor with the staff in the emergency department

Intergroup and interpersonal differences

The importance of one-to-one personal relationships

Not receiving the necessary respect

Communication and collaboration with patients and relatives

The importance of introducing oneself to patients
Obtaining permission for examination

Experiencing conflict management

4. Improvement in the clinical environment
Improvement in emergency emergency internship patient management during the

Improvement in procedural skills

Awareness of the concept and functioning of emergency services

Development of ability to work in a team

Postgraduate level of competence in emergency patient management
Recognition of unstable patients

Stabilizing unstable patients

Transporting unstable patients correctly

Importance of experience

Importance of using algorithms

\section{Thoughts on the simulation-based preparation program}

Students generally stated that the SBE Clinical Preparation Program was inclusive, its content was sufficient and the program was well structured. Before starting the internship in the clinic, they stated that what they learned at the CASE increased their self-confidence and facilitated the process of getting used to the clinic. The students suggested that management of stable patients be added to the program and that, if possible, arterial blood gas and liquid electrolyte therapy should be included in the program.

G2K3: "I think it has been very useful forunstable patients. Mostly stable patients come here, but when the unstable patients came, we knew what to focus on thanks to the training we received at the CASE." 
G3K2: "All patients were mentioned in the CASE. Cardiac, respiratory, CVO, acute abdominal pain."

Within the scope of the clinical environment preparation subtheme, the students stated that the training at the CASE prepared them well for the clinical management of unstable emergency patients and cardiopulmonary resuscitation, but they learned the skills needed for the management of stable patients by encountering them in the clinical environment. They stated that because of the SBE program, they were especially well prepared to identify and evaluate emergency patients and perform the necessary intervention, but they needed more practice in requesting permission to examine patients and planning the treatment.

G1K5: "The most important thing to me was anaphylactic shock in the clinic. I remembered that we did the same at the CASE; I knew what to do.

G2K4: "I noticed that I have adopted the algorithms. I realized that I was approachingthe patient faster and more accurately using algorithms. So, the CASE has been very useful."

\section{Experiences in the clinical setting}

The trainers stated that in the first week after beginning their internship, the students had difficulty transferring what they knew to the clinic setting. Although they had successfully applied it in the simulator, they had difficulty visualizing and applying the algorithms they had learned to real patients with the patients' relatives looking on. They stated that the simulation program prepared the students well for the clinic and gave them a foundation, which was very important. However, the trainers added that, the students had to overcome an emotional barrier when approaching real patients, a process that took 1-2 weeks.

E1: After a week ina real clinical setting, they get used to the environment. After that, they began to recall everything they did at the CASE and apply it to the patients.

E2: Actually, they transferred the training at the CASE very well to the clinic here. The training there allowed them to create an algorithm in their minds.

Regarding clinical experiences, most of the students stated that they had an adjustment period of 1-2 weeks after they entered the clinic and that they felt more secure in the clinic after the training they received at the CASE. However, in the clinic, they also stated that they had to get used to the working environment in various respects related to relations with patients' relatives and other healthcare professionals and the recognition of their roles and responsibilities. They emphasized that when they are given more responsibility at the bedside, they felt much better.

G1K1: "I wasn't always sure of my feeling here. For example, when I first arrived, I did not fully grasp that everything was already done and what I had to do as an intern." 
G3K2: "Management of difficult patients was really difficult for me. For example, there was a code blue, and the patient's relative was crying. I also tried to talk to the patient's relative and inform him."

The trainers observed that the interns had difficulty managing the emotional process in unstable patients and telling this to the relatives of the patients.

E1: "I think their technical skills were sufficient. For example, I think they had good knowledge of resuscitation. Here, there were factors other than technical skills when applying it to real patients. While ventilatingthe patient, there were those who were tearful and crying, and such emotional moments were experienced."

The students stated that they could not see a sufficient variety of patients in the clinical environment and that they did not encounter many unstable patients coded as red; instead, most of the cases were stable and coded as green. Although the interns did not frequently encounter unstable patients, they added that they could easily handle such situations by remembering the algorithms for emergency patient management that they learned in SBE training.

G2K4: "If you ask which patients you have seen the most here, fever and abdominal pain. The variety could have been more, but I think there is nothing to do about it; it's a bit a matter of luck."

G3K2: "It is always said that you have to meet at least 10 life-threatening patients; I could not meet alone.'

Interviews with the trainers indicated that the students saw a sufficient variety of patients in the emergency internship.

E2: "They all see. I cannot say that they lack a case. Okay, not many patients come, but the patients who come have multiple problems."

The students stated that defining their roles, especially in the clinical environment, is important not only for themselves but also for other healthcare professionals, patients and educators. They stated that they had difficulty in the clinical environment when the roles were not defined. They especially noted the communication problems they experienced with other healthcare professionals in front of patients and their relatives. They stated that their difficulty communicating and cooperating with some trainers and nurses in different learning environments was one of the most serious problems they had at the bedside in the clinic.

G2K2: "We had difficulties because our role as interns at X hospital was not fully defined."

G3K5: "I think an orientation program should have been prepared for us here when starting the internship. What we will do while standing at the counter, what we will do in the back, what is expected of us, etc."

During the interviews with the trainers on these themes, the most common difficulties mentioned by the students were communication and conflict management with other healthcare professionals and patients' relatives. 
E1: "I think it was more important to cross the threshold in the social area ofrelations with patients and their relatives and nurses rather than in their technical skills."

\section{Perceptions of the learning climate}

The opinions of the students regarding their education were that a supportive and positive learning environment was prepared them. They desired slightly more autonomy from their trainers in prescribing and ordering at the end of the internship.

G2K3: "I think we should be able to order here in the last weeks. I think I have this skill. Then they can check my work. But they should give us this responsibility before we finish and leave."

G3K5: "We have to take more responsibility. It is over now; we will do everything ourselves from now on."

The views of the trainers on these themes were as follows.

E2: "Yes, our only goal is to teach them something, I think they see it. I think this is probably effective. They are aware that we worry about them. I think they are aware that we are working so that they do not suffer after graduating from here."

When the learning climate was evaluated in terms of communication and cooperation with other healthcare professionals, the differences observed between groups and individuals were striking. Students who had difficulty in their relationships stated that they did not receive the necessary respect at the bedside and they were not accepted as doctors and that this situation put them in a difficult position at the bedside; in particular, some warnings and speaking styles were disrespectful.

G2K4: "You know you aren't wanted; you feel like you are excess. Even if they don't say anything, you feel like you are too much because of their behavior."

G2K1. "When a problem arose, I usually tried to solve it by communicating. Let our definition be clear so they understand."

The views of the trainers on this theme are as follows.

E1: "In the first adjustment period, we tell our friends(emergency department staff) that they will get used to you and here. That is why the first week expectations are low; they have a period of mutual adjustment. By the second week, everyone knows each other, and there is no problem. We give importance to communication with other healthcare professionals."

They stated that there were no major problems with the patients and their relatives. They explained that the reason for this was that if the interns introduced themselves to the patients, explained the situation and asked permission from the patient to examine them, they typically did not encounter any problems. They stated that some patients' relatives are aggressive in crisis situations, but the students can cope with these situations by providing the necessary information to the relatives. They added that other 
healthcare professionals are very successful in the management of conflicts regarding patients and their relatives. They also stated that patients' attitudes towards the interns during the bedside process affected their approach to the patient.

The opinion of one of the trainers about this was as follows.

E:2 "I have not received any complaints from the patients nor witnessed any disrespectful behavior."

\section{Improvement in the clinical environment}

The last major theme was the evaluation of further development during the clinical internship. Although the students thought that the CASE experience prepared them well for the clinical environment and that they did not see the number and variety of patients they expected during the clerkship, they stated that they improved significantly in clinical emergency patient management during the eight weeks. They added that they felt competent in identifying, stabilizing and directing emergency patients to the right place in primary care after graduation. They said that they saw patients and believed they would gain even more experience in the years to come. They also expressed that they were very confident in approaching unstable patients and performing the necessary intervention. The reason for this is that both the SBE program and the positive learning climate that the trainers especially established for them in the clinical environment were effective.

G2K4: "If I were to score improvement, it would be 1-2 before the CASE, 5 after the CASE, and 8-9 after the internship."

G4K1: "Initially, I felt like a student while working with the patient; towards the end of the internship, I started to feel like a doctor. This has been very good for me. But I wish we could see more patients."

The views of the trainers were as follows.

E2: "When they are alone with the patient, they learn how to talk to the patient and how to examine them. After a few weeks, the problem with this issue ends; at this time, the question of what I will prescribe and what tests I will request begins."

\section{Discussion}

In this study, in which the effectiveness of the SBE Clinical Preparation Program (focusing on emergency patient management) was evaluated. The participants stated that the SBE program prepared them very well for critical patient management, that the content of the program was sufficient, and that they were able to transfer the training they acquired in the simulated environment to the clinic. In the focus group discussions, the students stated that they felt more confident in approaching critical patients during their first weeks in the emergency department due to the SBE Clinical Preparation Program and that they were able to intervene in critical cases correctly because of the algorithms and applications they learned in the program. On the other hand, the trainers stated that in the first weeks of the clinical work, the students 
had difficulty transferring what they knew before coming to the clinic, and although they successfully applied their knowledge in the simulations, they had difficulty visualizing and applying those algorithms to real patients with the patients' relatives nearby. In addition, the trainers stated that the simulation program prepared the students well for the clinic, giving them a foundation, and this was very important. However, they had to overcome an emotional barrier in approaching real patients, a process that took 1-2 weeks.

In a study conducted by Kellett et al. in 2015 (4), students stated that they experienced high stress and anxiety during the first days of their professional life with regard to patient care, being alone, meeting other employees for the first time and making decisions about the patient alone. They stated that they felt pressure about what was expected of them due to their changed role.

Similarly, in our study, the trainers stated that the interns did not have serious deficiencies in knowledge and skills; they were able to apply what they learned in a simulated environment. However, they observed that students experienced difficulty in orientating themselves to the clinical environment, especially in the first week. They also added that the students experienced difficulties, especially in matters such as making quick decisions at the bedside in a limited time, performing interventions in front of patients and their relatives, communicating with nurses and managing conflict. In the focus group discussions, interns also evaluated the process they went through in a similar way.

In a study conducted by Barrett et al. in 2017 (29), students stated that effective communication with their peers, other healthcare professionals and patients is supportive of a positive learning environment, but intervention in real patients is always challenging. In our study, our students stated that they had an orientation program for getting used to the clinical setting, the patients and other health care professionals lasting 1 or 2 weeks. They also emphasized that they would have experienced many more difficulties if they had started their emergency internship directly without the preparatory training (the SBE program), and the SBE program was very useful in preparing them for the clerkship.

Regarding the adequacy of the clinical experiences they had during the emergency internship, almost all of the students stated that they did not see enough patients. The students stated that they did not encounter unstable patients very often but typically saw outpatients with lower and upper respiratory tract infections and gastroenteritis in the area coded green. In Turkey, the majority of patients visiting the emergency department are cared for in the green and yellow areas (meaning that they are not true emergency cases), and this situation changes the quality of clinical training. This situation also points to the necessity of the introduction of SBE trainings in which clinical environments are simulated to overcome problems arising from the context of the country and the hospital and the number and variety of patients.

In a study conducted by Brennan et al. in 2010 (3), it was stated that graduates felt inadequate, especially in prescribing; experienced uncertainty about what was expected of them in the clinic at the bedside; had emotional difficulties coping with death and poor patient progress; and had difficulty participating in multidisciplinary teams with other doctors. Likewise, in our study, most of the interns stated that they did 
not have enough experience with prescribing and that they would have trouble on this point when they graduated. In addition, the interns stated that they need clearer definitions of their roles and responsibilities in the clinical setting. They stated that the more they can take responsibility and act autonomously under the supervision of a supervisor, the better they can improve themselves.

In a qualitative study conducted by Tallentine et al. in 2011 (12), the authors evaluated the difficulties encountered in the context of acute patient care under three main themes: cognitive difficulties, roles and responsibilities, and environmental factors. The subthemes related to cognitive difficulties that emerged were transferring knowledge and skills to the clinic, making decisions and dealing with complex situations. During the clinical transfer process, it was determined that the participants had mastery of the algorithms in terms of knowledge and skills, but they had difficulty applying them in various clinical situations. The participants also stated that they had difficulty making decisions and coping with complex situations. They added that they did not encounter these difficulties, especially regarding urgent and unstable patients, during their medical education process, and that they did not have relevant experience. The subthemes that emerged in relation to roles and responsibilities were associated with fear of harming the patient. Another main theme that emerged in the study of Tallentine et al. was related to environmental factors. Under this theme, factors such as the medical hierarchy and the obligation to intervene under stress were identified. The themes that emerged in this study regarding the problems and difficulties encountered in clinical education were as follows: "Uncertainty in roles and responsibilities", "communication and social/interactive problems with patients and their relatives and other healthcare professionals", "intensity of working hours", "immediate intervention in case of failure", "not being accepted as a doctor and being seen as a burden" and "not receiving the necessary respect at the bedside".

The effectiveness of the training programs and the unique features of the students (motivation, anxiety levels) in the transfer of the learned subjects to the clinic, the quality of the processes experienced during application (seeing sufficient patients, communication and in-depth interaction with healthcare professionals and patients) and the environment and context in which these practices take place (learning climate, clinical climate, learning culture, etc.) are also of great importance. The training that takes place in simulated and real clinical environments can differ according to the different learning and evaluation environments/contexts in which it takes place, so it is necessary to consider this factor in program evaluation processes.

\section{Limitations}

One limitation of our study is that the qualitative methodology used was not designed to produce generalizable results beyond the study participants, although, as found here, the design provides useful insight into Turkish medical students' perspectives of SBE. Another is the limited recruitment of the students from only one university in Istanbul.

\section{Conclusion}


SBE transition programs are effective in preparing students for the next education phase and the clinic and in facilitating the transition between phases. SBE programs are not sufficient of themselves, and these programs should be developed in a continuous and integrated manner with training programs in actual clinical settings.

\section{Abbreviations}

SBE: Simulation based education

\section{Declarations}

\section{Ethics approval and consent to participate}

Ethics approval was obtained from the Acibadem Mehmet Ali Aydinlar University Ethics Board (Reference number 20197). Informed consent was obtained from all participants prior to attending the sessions.

\section{Consent for publication}

Consent for publication has been obtained from all authors of this study.

\section{Availability of data and materials}

The data sets generated and or analysed during the current study are not publicly available due to participant privacy could be compromised but anonymsed versions are available from the corresponding author on reasonable request.

\section{Competing interests}

There are no financial and non-financial competing interests in this study.

\section{Funding}

This study has not been funded by any institution.

\section{Authors' contributions}

This research was designed by Dilek Kitapcioglu and Mehmet Ali Gulpinar. Collection of data in the form of focus groups and interviews were conducted by Dilek Kitapcioglu and Ozlem Tanriover. Coding and analysis of data were performed by Dilek Kitapcioglu,Ozlem Tanriover,Sinem Yildiz Inanici and Mehmet Ali Gulpinar.Mehmet Emin Aksoy contributed to editing and writing the manuscript. All authors have read and approved the final manuscript.

\section{Acknowledgements}

Not applicable. 
Not applicable

\section{References}

1. Beane A, Padeniya A, De Silva AP, et al. Closing the theory to practice gap for newly qualified doctors: evaluation of a peer-delivered practical skill training course for newly qualified doctors in preparation for clinical practice. Postgraduate Medical Journal.;2017,93:592-6.

2. Blakley A, Brennan N. Does undergraduate curriculum design make a difference to readiness to practice as a junior doctor? Medical Teacher 2011; 33: 459-467.

3. Brennan N, Corrigan O, Allard J, Archer J, Barnes R, Bleakley A, Collett T and Regan de Bere S. The transition from medical student to junior doctor: today's experiences of Tomorrow's Doctors. Medical Education 2010:44: 449-458

4. Kellett J, Papageorgiou A, Cavenagh P, Salter C, Miles S and Leinster S. J. The preparedness of newly qualified doctors - Views of Foundation doctors and supervisors. Medical Teacher 2015; 37: 949954.

5. O'Brien BC and Poncelet AN. Transition to Clerkship Courses: Preparing Students to Enter the Workplace. Academic Medicine,.2010; Vol. 85, No. 12

6. Okusanya OT, Kornfield ZN, Reinke CE The effect and durability of a pregraduation bootcamp on the confidence of senior medical student entering surgical residencies. Journal of Surgical Education.2012;69:536-543

7. Peyre SE, Peyre CG, Sullivan MA surgical skills elective can improve student confidence prior to internship. Journal of Surgical Resuscitation.2006;133:11-15

8. Poncelet A and O'Brien B. Preparing Medical Students for Clerkships: A Descriptive Analysis of Transition Courses. Academic Medicine. 2008; Vol. 83, No. 22

9. Sajitha R, Prince C, Kirubah D, Venkatesan S Perceptions of the preparedness of medical graduates for their responsibilities as "physicians of first contact": a pilot study. Journal of Contemporary Medical Education 2016

10. Ester RM, Henzi DL, Cohn SM. Senior medical student bootcamp: can result in increased self confidence before starting surgery internships.Current Surgery 2006;63:264-268

11. Zeng W, Woodhouse J, Brunt M Do preclinical background and clerkship experiences impact skills performance in an accelerated internship preparation course for senior medical students? Surgery $2010 ; 148(4): 768-76$

12. Tallentire V, Smith S, Skinner J and Cameron HS. Understanding the behaviour of newly qualified doctors in acute care contexts. Medical Education 2011;45: 995-1005

13. Brunt LM, Halpin VJ, Klingensmith ME. Accelerated skills preparation and assessment for senior medical students entering surgical internship. Journal of American College of Surgeons 2008; 
206:897-907

14. Cohen ER. Barsuk, JH, Moazed, F; Caprio T, Didwania A McGaghie, WC, Wayne, DB. Making July Safer: Simulation-Based Mastery Learning During Intern Boot Camp. First published online December 23,2012

15. Datta R, Upadhyay KK, Jaideep JN Simulation and its role in medical education.Medical Journal Armed Forces India 2012;68(2):167-172

16. Cook DA., Hatala R.,Brydges R Zendejas B, Szostek JH,Wang AT, Erwin PJ, Hamstra, SJ. TechnologyEnhanced Simulation for Health Professions Education A Systematic Review and Meta-analysis. JAMA. 2011;306(9):978-988

17. Hogg $G$ and Miller D. The effects of an enhanced simulation programme on medical students' confidence responding to clinical deterioration. BMC Medical Education 2016;16:161.

18. Kitapcioglu D, Topsever P, Şahiner M, Bakırcı N. Mezuniyet Öncesi Tıp Eğitiminde Simülasyon Merkezlerinin Yeri. Türkiye Klinikleri Özel Sayı.2017

19. Voelker W, Petri N, Onissen C, SteOrk S, BirkemeyerR, Kaiser E, and Oberhoff M Does SimulationBased Training Improve Procedural Skills of Beginners in Interventional Cardiology?A Stratified Randomized Study. Journal of Interventional Cardiology .2016; Vol. 29, No. 1

20. Durning SJ, Artino AR. Situativity theory: A perspective on how participants and the environment can interact: AMEE Guide no. 52. Medical Teacher, 2011; 33:3, 188-199.

21. Eberle J, Stegmann K, Fischer F. Legitimate Peripheral Participation in Communities of Practice: Participation Support Structures for Newcomers in Faculty Student Councils, Journal of the Learning Sciences, 2014; 23:2, 216-244, DOI: 10.1080/10508406.2014.883978

22. Gülpınar MA. İşbaşında/Klinikte Öğrenme, Klinik Kültür/İklim ve Olumlu Öğrenme İklimi Oluşturma. Türkiye Klinikleri, Tıp ve Sağlık Bilimlerinde Eğitim Yöntem ve Teknikleri Özel SayıSı,(2016)1(1), $48-58$

23. Kelly J. Caverzagie KJ, Goldenberg M G., Hall JM. Psychology and learning: The role of the clinical learning environment. Medical Teacher 2019; Vol. 41, No. 4, 375-379

24. Yardley S, Teunissen PW, Dornan T. Web Paper Amee Guide: Theories in Medical Education Experiential Learning: Amee Guide No. 63

25. Ohlman E, Alinaghizadeh H, Kaila P, Hult H, Nilsson GH Salminen H Adaptation and validation of the instrument Clinical Learning Environment and Supervision for medical students in primary health care. BMC Medical Education 2016; 16:308

26. Platts $D$, Burrows $M$. Medical student evaluation of measuring engagement in clinical learning. Education for Primary Care, 2018; VoL 29, no. 2, 122

27. Snadden D. Clinical education: context is everything. Medical Education 2006; 40: 97-98

28. Frye AW, Hemmer PA Program evaluation models and related theories: AMEE Guide No. 67. Medical Teacher; 34:5, e288-e299.

29. Barrett J, Trumble S, McColl G. Novice students navigating the clinical environment in an early medical clerkship. Medical Education. 2017;51: 1014-1024. 


\section{Supplementary Files}

This is a list of supplementary files associated with this preprint. Click to download.

- AdditionalFile1.docx

- AdditionalFile2.docx 